\title{
year in review
}

\section{The Yearbook}

We take stock of who made headlines this year for enlightening or disappointing us in 2021.

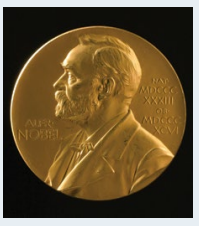

Credit: Science \& Society Picture Library / SSPL / Getty

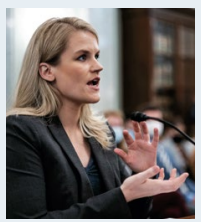

Credit: Pool/ Getty Images News / Getty

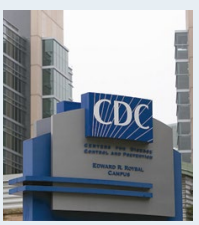

Credit: Jessica McGowan / Stringer / Getty Images News / Getty

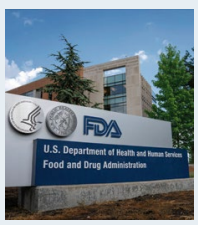

Credit: Sarah

Silbiger /

Stringer / Getty Images News / Getty

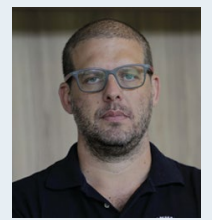

The Nobel Prize awarders

Most likely not to award a prize to a woman

This year, the nearly all-male list of Nobel Prize awardees did not go unnoticed. Only 1 of the 13 Nobel laureates was a woman - the Philippine journalist Maria Ressa shared the Nobel Peace Prize with Russia’s Dmitry Muratov for their efforts to safeguard freedom of expression. In the history of the prize, only 58 women have ever been named a Nobel laureate - Marie Curie was honored twice, in 1903 in Physics, and in 1911 in Chemistry. That makes them only $6 \%$ of the total of 943 people who have received this honor. Speaking about the issue, Göran K. Hansson, secretary general of the Royal Swedish Academy of Sciences, said that "it is sad that there are so few women Nobel laureates," but seemed to dismiss the possibility of taking action to increase their representation in the Nobel's ranks.

\section{Frances Haugen}

Most likely to tell you what Facebook is really up to

Facebook practices and policies have been under scrutiny for a while, to little effect. The tide began to turn in September, when the Wall Street Journal published the first installment of 'The Facebook Files', a series of investigative stories "based on a review of internal Facebook documents, including research reports, online employee discussions and drafts of presentations to senior management." On October 3, Frances Haugen, a former product manager in the Facebook civic integrity department, came forward as the whistleblower. Haugen gathered and leaked tens of thousands of internal documents that are helping to unveil how much Facebook knew about the harms that its platforms could cause, raising concerns about the company's willingness and ability to respond to these damages. Among them are allegations that Facebook knew that its Instagram platform was harmful to young users - with teenage girls being the most impacted and that the platform has served as vehicle for misinformation during the ongoing COVID-19 crisis.

\section{The CDC}

Most likely to confuse the public

In May, the Centers for Disease Control and Prevention (CDC) managed to confuse nearly everyone with a sudden change in mask-wearing recommendations for people fully vaccinated against COVID-19, without clear guidance on when and where masks were still recommended and without coordination with federal or local governments. The CDC also failed to convey to the public that those recommendations could change, should the situation evolve - which is exactly what (predictably) happened just a few months later with the arrival of the SARS-CoV-2 Delta variant.

\section{The US FDA}

Most unlikely to follow expert advice

In June, the US Food and Drug Administration (FDA) granted the drug aducanumab accelerated approval for the treatment of people with Alzheimer's disease. The decision had an overwhelming lack of support from the FDA's own advisory committee, was followed by the resignation of several committee members and expressions of concerns and disapproval by specialists in the field, and ultimately left doctors and patients unsure about what to do.

\section{Pedro Hallal}

Most likely to set the record straight

Attacks on scientists have increased during the COVID-19 pandemic, but this has not deterred them from speaking out. Pedro Hallal, a Brazilian epidemiologist and associate professor at the Federal University of Pelotas, in Brazil, has been outspoken about the calamitous handling of the pandemic by President Bolsonaro, who is openly anti-science. Hallal says that the Bolsonaro government also censored and discontinued studies that reported that the indigenous people of the Amazon were at much greater risk of dying from COVID-19 than was the rest of the population. 


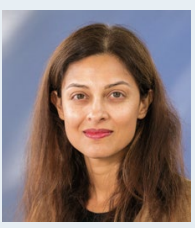

Credit: Roberto Ricciuti /

Getty Images

Entertainment /

Getty

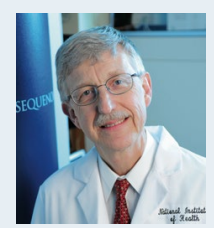

Credit: Michael

Ventura /

Alamy Stock

Photo

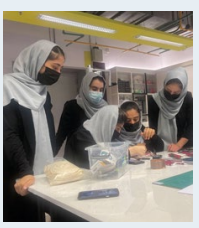

Credit: Digital

Citizen Fund

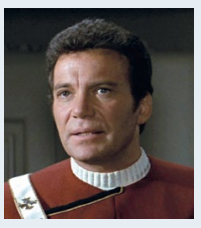

Credit: CBS

Photo Archive /

CBS / Getty

\section{Devi Sridhar}

Most likely to give the public trustworthy information

Devi Sridhar, who is a professor and the chair of Global Public Health at the University of Edinburgh, UK, has worked tirelessly to hold government and public-health officials accountable during the pandemic. Beyond her academic work, Sridhar also writes frequently about global health and COVID-19 for general audiences and has a new book upcoming on the politics of pandemics and how to stop the next one.

\section{Francis Collins}

Most well-deserved retirement

As the longest-serving director in the history of the US National Institutes of Health (NIH), Francis Collins has weathered political storms and led ambitious projects that changed the landscape of research into neurodegenerative disease, cancer, precision medicine and COVID-19, although his tenure has not been without criticism. Collins has been an outspoken advocate for diversity, equality and inclusion at the NIH - an institution that has only had one female director, Bernadine Healy, over two decades ago. Although he is stepping down from his leadership role, Collins will go back to the lab and will continue to lead his research group there.

\section{The Afghan Dreamers}

Most likely to turn adversity into innovation

In 2020, Elham Mansori, Florence Poya, Nahida Khajazadeh and Somaya Farooqi built a low-cost ventilator out of car parts. They are part of the Afghan Dreamers robotic team formed in 2017 by the Afghan tech entrepreneur Roya Mahboob. A year later, with a change of regime in Afghanistan and dim prospects for women's education, they also had to seek safe haven abroad. Somaya and other members landed in Doha in August this year, where they plan to further hone their skills in artificial intelligence and robotics. Others have been granted asylum in Mexico; they say that "we didn't want our history to be ended by Taliban" and that they will continue to work to improve conditions in their home country.

\section{William Shatner}

Most striking case of life imitating art

When the actor William Shatner flew on Jeff Bezos' Blue Origin shuttle in October, he became the oldest person in space, at age 90. Shatner, who played Captain James T. Kirk on Star Trek, spent 11 minutes above the Kármán Line, recognized as the boundary of space, and reached an altitude of 66.5 miles, including 3-4 minutes of weightlessness. The health effects of space flight, including those from microgravity, on either physically fit astronauts or nonagenarians are still not well understood. Star Trek existed in a somewhat utopian world without money, something that may be food for thought for billionaire, Amazon founder, and Star Trek fan Jeff Bezos, who covered the costs for Shatner's flight (and has made US\$100 million selling tickets to other space tourists). 